\title{
Strategi Peningkatan Ekuitas Merek di Indonesia
}

\author{
Kussuyatmono Bagus Wardianto ${ }^{1, *}$, Damayanti ${ }^{2}$, Mediya Destalia $^{3}$, Supriyanto $^{4}$ \\ 1,2,3,4 Jurusan Administrasi Bisnis, FISIP, Universitas Lampung \\ *Email: kussuyatmono.bagus@,fisip.unila.ac.id
}

\begin{abstract}
The purpose of this study is to test whether Debt, Profitability, and investment significantly influence brand equity. Brand equity in this study was measured using brand value calculated through the Hirose Method (2002). Capital structure was measured through the amount of debt, profitability was measured through the net income amount, and investment was measured theough the Acquisitions of fixed assets total. The sample was the Goods-Consumption Sector Company listed on the Indonesia Stock Exchange for 2012-2017 period. Existing data were analyzed using multiple linear regression and processed using eviews version 10. The results of statistical tests indicate that profitability and investment have a significant effect with brand equity. While the debt has no significant effect with brand equity.
\end{abstract}

\begin{abstract}
Abstrak: Tujuan penelitian ini adalah untuk menguji apakah utang, profitabilitas dan investasi secara signifikan mempengaruhi ekuitas merek. Ekuitas merek dalam penelitian ini diukur dengan menggunakan nilai merek yang dihitung melalui Metode Hirose (2002). Utang diukur dengan menggunakan jumlah utang, profitabilitas diukur dengan menggunakan jumlah laba bersih dan investasi diukur dengan menggunakan jumlah acquisitions of fixed assets. Sampel yang diteliti adalah perusahaan sektor barang konsumsi yang listed di Bursa Efek Indonesia (BEI) periode 2012-2017. Data yang ada dianalisis menggunakan regresi linier berganda, pengolahan data menggunakan eviews versi 10. Pengujian statistik menunjukkan bahwa profitabilitas dan investasi berpengaruh signifikan terhadap ekuitas merek. Sedangkan utang tidak berpengaruh signifikan terhadap ekuitas merek.
\end{abstract}

Keywords: Brand Equity; Debt; Profitability; Investment

\section{Latar Belakang}

Semenjak maraknya pembahasan mengenai merger dan akuisisi pada tahun 1980-an ekuitas merek adalah topik yang penting diulas dalam praktek maupun kajian bisnis (Huang, 2015; Hasan et al., 2015; dan Wardianto et al, 2018). Ekuitas merek ini digunakan sebagai dasar dalam menghitung goodwill dan reputasi perusahaan ketika terjadi merger dan akuisisi (Eng \& Keh, 2007). Ditambahkan oleh Davcik (2013) bahwa ekuitas merek dianggap sebagai asset bisnis perusahaan yang penting sekali dewasa ini.

Perusahaan dengan ekuitas merek yang baik dapat mencapai keunggulan bersaing di pasar. Hal ini sesuai dengan konsep resource based-view (RBV). RBV, sebagaimana pendapat dari Penrose (1959), bahwa pertumbuhan perusahaan yang berkelanjutan didasarkan pada karakteristik internal perusahaan. Kemudian, RBV menurut Wernerfelt (1984) bahwa keunggulan kompetitif berkelanjutan suatu perusahaan berasal dari beragam sumber daya di dalam perusahaan. Ekuitas merek merupakan karakteristik internal yang diusulkan dalam penelitian ini sebagai aset tidak berwujud yang penting untuk keunggulan kompetitif berkelanjutan suatu perusahaan.

Ekuitas merek sebagaimana konsep signaling theory, yaitu salah satu asumsi yang dijadikan sebagai dasar pemikiran penelitian ini adalah adanya asimetri informasi (Bhattacharyya, 1979). Hal ini karena pihak manajemen perusahaan merupakan pemegang informasi yang dominan dibandingkan pihak luar. Sehingga dengan adanya asimetris informasi, maka fungsi merek adalah sebagai kredibilitas sinyal pasar (Erdem and Swait, 1998). Kredibilitas sinyal menurut Signaling theory menentukan efektifitas sinyal pasar dalam menyampaikan informasi (Tirole, 1990). Sinyal merek karena kredibel maka informasi tentang posisi merek yang dikomunikasikan kepada konsumen dan investor oleh perusahaan dianggap benar dan dapat diandalkan.

Mengingat pentingnya ekuitas merek ini maka faktor-faktor yang mempengaruhinya perlu dikaji dan perlu diperhatikan, antara lain utang, profitabilitas dan investasi perusahaan. Penelitian mengenai faktor- 
faktor yang mempengaruhi ekuitas merek dalam perspektif keuangan masih jarang ditemui. Hal ini karena masih kuatnya persepsi bahwa ekuitas merek merupakan kajian bidang pemasaran bukan kajian bidang keuangan. Sepanjang pengamatan peneliti hanya penelitian yang dilakukan oleh Muqaddas and Ahmad (2016) dengan kesimpulan bahwa profitabilitas dan investasi mempengaruhi ekuitas merek perusahaan.

Sehingga penelitian tentang ekuitas merek dalam perspektif keuangan ini merupakan novelty penelitian ini. Muqaddas and Ahmad (2016) dalam penelitiannya tidak memasukkan variabel struktur modal, sehingga hal ini juga menjadi novelty dalam penelitian ini. Penelitian tentang ekuitas merek ini dilakukan pada perusahaan sektor barang konsumsi yang listed di Bursa Efek Indonesia (BEI) selama periode 2012 sampai dengan 2017.

\section{Review Literatur}

Merek merupakan "identitas yang berupa nama dan atau atau simbol (yaitu, logo, merek dagang, atau desain paket) yang melekat pada barang atau jasa dari salah satu penjual atau kelompok penjual sebagai pembanding barang-barang atau jasa dari para pesaing" (Hirose et al., 2002; Aaker, 1991). Bahkan keberadaan merek telah ada sejak lama untuk membedakan produk dari berbagai perusahaan (Varma et al., 2018).

Ekuitas merek merupakan "kemampuan sebuah merek untuk mendapatkan nilai arus masa depan, baik melalui kepasitasnya untuk mengambil harga premium dari konsumen, atau melalui kepasitasnya untuk menarik modal, atau memfasilitasi hubungan dengan pihak yang berkepentingan" (Arvidsson, 2006). Keller (2003) mendefinisikan ekuitas merek sebagai "nilai tambah bahwa produk mencapai hasil dari investasi masa lalu dalam kegiatan pemasaran untuk merek tersebut".

Nilai merek sesungguhnya yang menambah produk sangat penting untuk mengelola nilai tambah dari sebuah merek (Cobb-Walgren et al., 1996). Perspektif empat pemain utama yang dapat digunakan untuk memahami konsep ekuitas merek adalah investor atau pemilik merek, produsen (producer), pengecer (retailer), dan konsumen atau pelanggan (Ukiwe, 2009), di mana merek menambah nilai produk untuk masing-masing empat pemain utama ini.

Ekuitas merek menjadi sangat penting untuk dikelola dengan baik oleh perusahaan. Untuk itu perlu diketahui apa saja yang bisa mempengaruhi ekuitas merek ini. Struktur modal, menurut Paramasivan and Subramanian (2012), mengacu pada jenis surat berharga dan jumlah proporsionalnya yang membentuk kapitalisasi. Secara umum, struktur modal merupakan gabungan antara utang dan ekuitas perusahaan (Ehrhardt and Brigham, 2011). Perusahaan yang menggunakan utang dalam struktur modalnya memberikan sinyal bahwa reputasinya diakui oleh debitur. Sehingga semakin baik reputasi ini maka ekuitas juga semakin baik, termasuk pelanggang, pemasok dan sebagainya.

Profitabilitas adalah hasil yang diperoleh perusahaan, selisih antara pendapatan dan biaya-biaya yang merupakan dampak dari strategi yang dilakukan oleh perusahaan (Ehrhardt and Brigham, 2011). Artinya profitabilitas ini menunjukkan kinerja perusahaan. Sehingga ketika profitabilitas meningkat menunjukkan kinerja perusahaan semakin baik. Peningkatan kinerja, melalui peningkatan profitabilitas ini, bisa meningkatkan reputasi atau ekuitas merek perusahaan. Hal ini sesuai dengan hasil penelitian yang dilakukan oleh Muqaddas and Ahmad (2016) di mana profitabilitas berpengaruh signifikan terhadap ekuitas merek.

Investasi adalah komitmen untuk satu atau lebih aset yang akan diadakan untuk beberapa periode waktu di masa depan dengan beberapa harapan keuntungan (Sajid et al., 2016). Investasi yang dilakukan oleh perusahaan merupakan sinyal bahwa perusahaan memiliki prospek yang baik di masa depan. Sehingga hal ini membuat reputasi perusahaan meningkat. Di mana reputasi ini merupakan indikator yang penting untuk mengukur ekuitas merek. Hal ini sesuai dengan hasil penelitian yang dilakukan oleh Muqaddas and Ahmad (2016) di mana investasi berpengaruh signifikan terhadap ekuitas merek. Berdasarkan kajian ini, maka dalam penelitian ini dihipotesiskan sebagai berikut:

$\mathrm{H}_{1}$ : Utang berpengaruh signifikan terhadap ekuitas merek 
$\mathrm{H}_{2}$ : Profitabilitas berpengaruh signifikan terhadap ekuitas merek

$\mathrm{H}_{3}$ : Investasi berpengaruh signifikan terhadap ekuitas merek

\section{Metode}

Pengukuran Variabel

Penelitian ini sesuai dengan Wardinto, et al. (2018) dimana ekuitas merek dihitung berdasarkan nilai merek menggunakan Model Hirose (Hirose et al., 2002). Model Hirose, et al. (2002) ini mengasumsikan nilai merek sebagai fungsi dari tiga faktor utama, yaitu:

$B V=f(P D, L D, E D, r)=\frac{P D}{r} * L D * E D$

Sumber: Hirose, et al. (2002)

Di mana: BV adalah Brand Value;PD adalah prestige driver; $\mathrm{LD}$ adalah loyality drive; $\mathrm{ED}$ adalah extension driver; dan $r$ adalah riskfree interest (discount) rate.

Prestige Driver (PD) adalah arus kas yang dihasilkan dari benefit harga atau nilai lebih dari merek. PD secara lebih detail diformulasikan melalui persamaan berikut ini:

$$
P D=\frac{1}{5} \sum_{i=-4}^{0}\left\{\left[\frac{S_{i}}{C_{i}}-\frac{S^{*} i}{C^{*} i}\right] * \frac{A D i}{O_{i}}\right\} * C_{0}
$$

Sumber: Hirose, et al. (2002)

Di mana: $P D$ adalah prestige driver; $S_{i}$ adalah sales of firms; $C_{i}$ adalah cost of sales of firms; $S_{i}^{*}$ adalah sales of a benchmark company; $C^{*}{ }_{i}$ adalah cost of sales a benchmark company; $A D$ adalah advertising expense and promotion cost; dan $O E$ adalah total operation expenses.

Loyality Driver (LD) merupakan kemampuan sebuah merek untuk menjaga stabilitas penjualan dalam jangka waktu yang panjang berkat kesetiaan dan kesediaan pelanggan dalam mengulangi pembelian terhadap merek yang sama. LD adalah stabilitas harga pokok penjualan. LD dihitung dengan menggunakan persamaan berikut ini:

$$
L D=\frac{\mu c-\sigma c}{\mu c}
$$

Sumber: Hirose, et al. (2002)
Di mana: LD adalah loyality driver; $\mu_{\mathrm{c}}$ adalah five-year average of firms' cost of sales; $\sigma_{c}$ adalah five-year standard deviation of firms' cost of sales

Extension Driver (ED) merupakan kemampuan ekspansi merek, maksudnya adalah mencerminkan kemampuan merek terkenal untuk memperluas jaringan bisnisnya ke seluruh sektor industri yang berbeda dan wilayah geografis lainnya. Rumus yang digunakan untuk mengkuantifikasikan ED dalam penelitian ini adalah sebagai berikut:

$$
E D=\frac{1}{2} \sum_{i=-1}^{0}\left\lfloor\frac{S X_{i}-S X_{i-1}}{S X_{i-1}}+1\right\rfloor
$$

Sumber: Hirose, et al. (2002)

Di mana: ED adalah extension driver; $S X$ adalah sales from non-core and oversea business.

Utang merupakan bagian dari komposisi struktur modal perusahaan bersama dengan ekuitas (Ehrhardt and Brigham, 2011). Sehingga utang dalam penelitian ini diukur dengan menggunakan besarnya utang yang ada di dalam neraca. Profitabilitas merupakan hasil bersih dari serangkaian kebijakan dan keputusan. Dalam penelitian ini indikator profitabilitas perusahaan yang digunakan adalah laba bersih setelah pajak yang ada pada laporan laba-rugi. Investasi adalah komitmen untuk satu atau lebih aset yang akan diadakan untuk beberapa periode waktu di masa depan dengan beberapa harapan keuntungan. Investasi dalam penelitian ini diukur dengan menggunakan acquisitions of fixed assets (AFA).

\section{Populasi dan Sampel}

Data dalam penelitian ini menggunakan data panel, yaitu daya gabungan dari data cross section yang berupa perusahaan dan data time series mulai 2012-2017. Populasi dalam penelitian ini adalah semua perusahaan sektor barang konsumsi yang di Bursa Efek Indonesia tahun 2012-2017. Sampel yang diteliti adalah perusahaan sektor barang konsumsi yang terdaftar di Bursa Efek Indonesia tahun 2012-2017 yang 
Tabel 1. Tabel Statistik Deskriptif

\begin{tabular}{lrrrr}
\hline & BV & Utang & Laba & \multicolumn{1}{c}{ AFA } \\
\hline StDev & 179.283 .971 .465 .648 & 9.786 .197 .274 .130 & 2.847 .653 .384 .674 & 1.349 .637 .704 .001 \\
\hline Mean & 70.212 .260 .768 .365 & 5.246 .468 .854 .020 & 1.760 .704 .060 .499 & 764.526 .158 .065 \\
\hline Median & 13.136 .870 .217 .751 & 809.334 .500 .000 & 281.530 .500 .000 & 190.785 .108 .106 \\
\hline
\end{tabular}

Sumber: Data diolah (2019)

konsisten menyampaikan laporan keuangannya, tidak pernah rugi dan memenuhi kriteria menurut metode Hirose. Sehingga diketahui unit analisis sebanyak 126 (21 perusahaan X 6 tahun).

\section{Teknik Analisis Data}

Analisis strategi peningkatan ekuitas merek yang dipengaruhi oleh struktur modal, ekuitas merek dan profitabilitas ini dianalisis menggunakan regresi linier berganda yang dibantu menggunakan alat analisis eviews versi 10.

\section{Hasil}

\section{Hasil Analisis Deskriptif}

Penelitian ini menguji peningkatan ekuitas merek bagi perusahaan yang dipengaruhi oleh struktur modal, profitabilitas dan investasi. Hasil analisis statistik deskriptif disajikan pada tabel 1.

Berdasarkan Tabel 1 diketahui rata-rata nilai merek adalah Rp70 trilyun, rata-rata utang sebesar Rp5 trilyun, rata-rata laba bersih sebesar Rp1,76 trilyun dan rata-rata acquisitions of fixed assets (AFA) adalah sebesar Rp765 milyar.

\section{Hasil Analisis Inferensial}

Analisis regresi dalam penelitian ini dilakukan dengan menggunakan fixed effect. Hasil analisis regresi dalam penelitian ini disajikan pada tabel 2 .

Tabel 2 menunjukkan bahwa persamaan regresi linier berdasarkan hasil penelitian ini adalah sebagai berikut:

$$
\begin{aligned}
& \mathrm{BV}=-2,83 \mathrm{e}+14+1,197 \mathrm{Utang}+ \\
& 158,5615 \mathrm{Laba}+88,1058 \mathrm{AFA}
\end{aligned}
$$

Nilai konstanta sebesar $-2,83 \mathrm{e}+14$ artinya ketika perusahaan tidak berutang, tidak memiliki laba dan tidak melakukan penambahan aktiva tetap maka nilai merek perusahaan akan mengalami penurunan sebesar Rp2,83e+14. Nilai 1,197 Utang artinya setiap upaya perusahaan menambah utangnya sebesar Rp1 dapat meningkatkan nilai mereknya sebesar Rp1,197. Adapun 158,5615Laba artinya setiap Rp1 laba yang

\begin{tabular}{|c|c|c|c|c|}
\hline Variable & Coefficient & Std. Error & t-Statistic & Prob. \\
\hline $\mathrm{C}$ & $-2.83 \mathrm{E}+14$ & $5.54 \mathrm{E}+13$ & -5.097348 & 0.0000 \\
\hline UTANG & 1.197406 & 5.061029 & 0.236593 & 0.8134 \\
\hline LABA & 158.5615 & 22.05893 & 7.188087 & 0.0000 \\
\hline AFA & 88.10576 & 31.33819 & 2.811450 & 0.0059 \\
\hline \multicolumn{5}{|c|}{ Effects Specification } \\
\hline \multicolumn{5}{|c|}{ Cross-section fixed (dummy variables) } \\
\hline R-squared & 0.657594 & Mean dependent var & & $7.02 \mathrm{E}+13$ \\
\hline Adjusted R-squared & 0.580385 & S.D. dependent var & & $1.79 \mathrm{E}+14$ \\
\hline S.E. of regression & $1.16 \mathrm{E}+14$ & Akaike info criterion & & 67.77909 \\
\hline Sum squared resid & $1.38 \mathrm{E}+30$ & Schwarz criterion & & 68.31933 \\
\hline Log likelihood & -4246.083 & Hannan-Quinn criter. & & 67.99857 \\
\hline F-statistic & 8.517035 & Durbin-Watson stat & & 1.704825 \\
\hline Prob(F-statistic) & 0.000000 & & & \\
\hline
\end{tabular}

Tabel 2. Fixed Effect

Sumber: Data, diolah (2019) 
diperoleh perusahaan dapat meningkatkan nilai merek sebesar Rp158,5615. Sedangkan 88,1058AFA artinya setiap upaya perusahaan menambah aktiva tetapnya Rp1 maka akan meningkatkan nilai merek sebesar Rp88,1058.

Berdasarkan tabel 2 diketahui bahwa nilai adjusted $R$-squared sebesar 0,580385. Nilai adjusted $R$-squared ini artinya bahwa model penelitian ini bisa digunakan untuk memprediksi ekuitas merek sebesar 58,04\%. Artinya struktur modal, profitabilitas dan investasi bisa digunakan untuk memprediksi ekuitas merek sebesar 58,04\%. Adapun sisanya sebesar $41,96 \%$ ekuitas merek dipengaruhi oleh variabel-variabel lain di luar penelitian ini.

Berdasarkan tabel 2 juga diketahui bahwa utang tidak berpengaruh terhadap ekuitas merek. Hal ini diketahui dari nilai probabilitasnya sebesar 0,8134 lebih besar dari toleransi kesalahan $(\alpha)$ yang diberlakukan yaitu sebesar $5 \% \quad(0,05)$. Artinya, utang tidak bisa digunakan untuk memprediksi variabilitas ekuitas merek dalam penelitian ini.

Profitabilitas dalam penelitian ini secara empiris terbukti berpengaruh signifikan terhadap ekuitas merek. Hal ini diketahui dari nilai probabilitasnya sebesar 0,0000 lebih kecil dari toleransi kesalahan $(\alpha)$ yaitu sebesar 5\% (0,05). Artinya, profitabilitas dalam penelitian ini bisa digunakan untuk memprediksi besar kecilnya ekuitas merek.

Sedangkan investasi dalam penelitian ini secara empiris terbukti berpengaruh signifikan terhadap ekuitas merek. Hal ini diketahui dari nilai probabilitasnya sebesar 0,0059 lebih kecil dari toleransi kesalahan $(\alpha)$ yaitu sebesar 5\% $(0,05)$. Artinya, investasi dalam penelitian ini bisa digunakan untuk memprediksi besar kecilnya ekuitas merek.

Masih berdasarkan tabel 2 diketahui nilai probabilitas (F-statistic) menunjukkan angka 0,0000 yang lebih kecil dari toleransi kesalahan $(\alpha)$ yang diberlakukan yaitu sebesar 5\% $(0,05)$. Hal ini berarti secara simultan struktur modal, profitabilitas dan investasi berpengaruh signifikan terhadap ekuitas merek.

Tabel 2 juga menunjukkan bahwa nilai Coefficient profitabilitas merupakan yang tertinggi diikuti oleh investasi, yaitu sebesar 158,5615 untuk profitabilitas dan 88,10576 untuk investasi. Hal ini berarti profitabilitas memiliki pengaruh paling kuat terhadap ekuitas merek.

\section{Pembahasan}

Penelitian yang dilakukan pada perusahaan sektor barang konsumsi yang listed di Bursa Efek Indonesia (BEI) tahun 2012-2017 ini bertujuan untuk menguji faktor-faktor yang dapat meningkatkan ekuitas merek perusahaan. Berdasarkan hasil analisis diketahui bahwa secara simultan struktur modal, profitabilitas dan investasi berpengaruh signifikan terhadap ekuitas merek.

Utang, yang diukur dengan menggunakan jumlah utang yang ada pada perusahaan tidak berpengaruh terhadap ekuitas merek. Berdasarkan tabel 1 diketahui bahwa perbandingan antara utang dengan acquisitions of fixed assets (AFA) yang sangat jauh. Artinya utang yang didapat oleh perusahaan sangat sedikit digunakan untuk investasi dalam bentuk membeli aktiva tetap yang sangat penting bagi perusahaan manufaktur. Sehingga penggunaan utang oleh perusahaan tidak bisa meningkatkan kinerja perusahaan secara signifikan.

Temuan ini menunjukkan ketidaksesuaian dengan konsep yang ada pada signaling theory. Berdasarkan signaling theory ini bahwa perusahaan yang mempunyai utang berarti perusahaan tersebut telah lolos dari ujian kelayakan dari kreditur. Artinya ketika kreditur memberikan pinjaman kepada suatu perusahaan, mereka yakin bahwa pinjaman itu akan dikembalikan oleh debitur.

Utang berpengaruh tidak signifikan terhadap ekuitas merek sesuai dengan konsep leverage irrelevant theory dimana penggunaan utang, dalam komposisi struktur modal perusahaan, tidak berpengaruh terhadap ekuitas merek. Ini menunjukkan bahwa ekuitas merek lebih dipengaruhi oleh basic earning perusahaan. Artinya ekuitas merek perusahaan lebih dipengaruhi oleh kinerja perusahaan, terutama kinerja keuangannya. Di mana kinerja perusahaan ini menunjukkan penerimaan masyarakat yang setia membeli produk perusahaan sehingga 
berimbas pada meningkatnya basic earning perusahaan.

Ekuitas merek lebih dipengaruhi oleh basic earning perusahaan sesuai dengan hasil temuan dalam penelitian ini. Hasil temuan dalam penelitian ini menunjukkan bahwa profitabilitas berpengaruh signifikan terhadap ekuitas merek. Berdasarkan temuan ini diketahui bahwa peningkatan profitabilitas dapat meningkatkan ekuitas merek. Hasil temuan ini konsisten dengan hasil penelitian Muqaddas and Ahmad (2016) di mana profitabilitas berpengaruh signifikan terhadap ekuitas merek.

Peningkatan profitabilitas ini menunjukkan adanya peningkatan kepercayaan konsumen yang mengkonsumsi produk yang dihasilkan oleh perusahaan. Kepercayaan konsumen ini merupakan hasil dari kepuasan dalam mengkonsumsi produk. Kepuasan dan kepercayaan ini bisa menjamin permintaan produk perusahaan dalam jangka panjang. Jaminan permintaan dalam jangka panjang ini bisa memberikan jaminan profitabilitas dalam jangka panjang juga. Akhirnya, profitabilitas meningkat maka ekuitas merek juga meningkat.

Ekuitas merek secara signifikan juga dipengaruhi investasi oleh perusahaan. Investasi tasi yang dilakukan oleh perusahaan ini meningkatkan kinerja perusahaan. Peningkatan kinerja ini bisa meningkatkan konsumen yang loyal pada perusahaan, sehingga bisa menjamin penjualan dan profitabilitas perusahaan dalam jangka panjang. Hal inilah yang membuat investasi secara signifikan berpengaruh terhadap ekuitas merek. Investasi berpengaruh signifikan terhadap ekuitas merek. Kesimpulan ini sesuai dengan hasil penelitian Muqaddas and Ahmad (2016).

Hasil temuan ini sesuai dengan konsep signaling theory, dimana perusahaan yang melakukan investasi menunjukkan bahwa prospek perusahaan di masa depan adalah baik. Prospek yang baik ini membuat konsumen merasa nyaman untuk mengkonsumsi produk mereka. Kondisi ini pada akhirnya membuat ekuitas merek bisa meningkat.

Hasil temuan ini sesuai dengan konsep Resources Based-View (RBV), dimana perusahaan yang memiliki keunggulan sumberdaya akan dapat memenangkan persaingan. Di sinilah pentingnya investasi yang dilakukan oleh perusahaan agar sumberdaya yang dimiliki perusahaan dapat menciptakan keunggulan bersaing. Keunggulan sumber daya ini juga bisa memberikan yang terbaik kepada konsumen dalam bentuk produk yang berkualitas.

Produk yang berkualitas ini bisa membuat konsumen yang telah mengkonsumsinya menjadi puas dan loyal. Kepuasan dan loyalitas ini bisa membuat pendapatan perusahaan terjaga dalam jangka panjang. Penjualan yang terjaga ini bisa membuat ekuitas merek menjadi kuat, karena reputasi perusahaan tidak diragukan oleh siapapun. Hal inilah membuat investasi bisa berpengaruh signifikan terhadap ekuitas merek.

Profitabilitas merupakan faktor yang dominan diikuti dengan investasi sebagai faktor penentu ekuitas merek. Artinya secara empiris menunjukkan bahwa ekuitas merek sangat dipengaruhi oleh penjualan yang dilakukan oleh perusahaan. Penjualan yang dilakukan perusahaan bisa memperkokoh posisi perusahaan di pasar. Dengan adanya penjualan ini maka profitabilitas bisa terjadi dan pada akhirnya ekuitas merek bisa meningkat juga.

\section{Implikasi Penelitian}

Secara teoritis penelitian ini sesuai dengan signaling theory, di mana profitabilitas dan dan investasi merupakan sinyal kondisi perusahaan yang baik. Sinyal baik ini kemudian direspon oleh masyarakat dengan setia membeli produk yang dijual perusahaan. Kondisi ini kemudian berimplikasi pada meningkatnya ekuitas merek perusahaan.

Hasil penelitian ini juga sesuai dengan leverage irrelevant theory karena penggunaan utang dalam struktur permodalan perusahaan tidak signifikan pengaruhnya terhadap ekuitas merek. Hal ini karena ekuitas merek lebih dipengaruhi oleh basic earning power.

Secara praktis penelitian ini menunjukkan bahwa profitabilitas sebagai basic earning power perlu diperhatikan. Profitabilitas merupakan hasil dari memenangkan persaingan di pasar, sehingga diperlukan investasi yang memadai agar perusahaan memiliki sumber daya yang 
unggul. Penelitian ini juga menunjukkan bahwa penggunaan utang dalam perusahaan pada hakekatnya penting tapi jumlahnya harus dikontrol. Penggunaan utang yang berlebihan dalam perusahaan bisa berakibat pada meningkatnya potensi kebangkrutan bagi perusahaan, sehingga bisa menurunkan ekuitas merek perusahaan.

\section{Kesimpulan dan Saran}

Penelitian ini menyimpulkan sebagai berikut: (1) utang tidak berpengaruh terhadap ekuitas merek; (2) profitabilitas berpengaruh signifikan terhadap ekuitas merek; dan (3) investasi berpengaruh signifikan terhadap ekuitas merek.

Profitabilitas sebagai basic earning power perusahaan perlu diperhatikan agar senantiasa terjaga stabilitasnya. Stabilitas profitabilitas ini perlu diperkuat melalui investasi yang tepat. Investasi ini antara lain pengadaan aktiva tetap, iklan \& promosi. Penggunaan dana dari utang perlu diperhatikan, karena penggunaan utang yang sedikit untuk investasi perusahaan justru tidak bisa meningkatkan kinerja perusahaan secara signifikan. Penelitian ini dikemudian hari bisa dikembangkan dengan memasukkan beberapa variabel lain yang mempengaruhi ekuitas merek, seperti iklan dan promosi dan sebagainya.

\section{Acknowledgement}

Penelitian ini didanai dari DIPA Universitas Lampung dengan nomor kontrak: 1990/UN26.21/PN/2019 tanggal 2 Juli 2019.

\section{Daftar Referensi}

Aaker, D. A. (1991). Managing brand equity: Capitalizing on the Value of a Brand Name. New York: Free Press.

Arvidsson, A. (2006). Brand value. Journal of Brand Management. 13(3): 188-192.

Bhattacharya, N. (1979). Imperfect Information, Dividend Policy, and the Bird in the Hand Fallacy. The Bell Journal of Economics, Vol. 10. No. 1, pp. 259-270.

Cobb-Walgren, C., Ruble, C., and Donthu, N. (1996). Brand Equity, Brand Preference, and Purchase Intent. Journal of Advertising, 24(3): 25-40.

Davcik, Nebojsa St. (2013). An empirical investigation of brand equity: drivers and their consequences. British Food Journal. Vol. 115 No. 9, 2013. pp. 1342-1360.

Eng, L. L., and H. T. Keh. (2007). The Effects of Advertising and Brand Value on Future Operating and Market Performance. Journal of Advertising, 36: 91-100.

Erdem, T. and J. Swait. 1998. Brand Equity as a Signaling Phenomenon. Journal of Consumer Psychology. 7(2). 131-157.

Hasan, M., K.T. Ullah and H. Bhattacharjee. (2015). Brand Valuation of Commercial Banks in Bangladesh: An Application of Marketing Profitability. Journal of Business Theory and Practice. Vol. 3, No. 2, 2015.

Hirose, Yoshikuni, Akiko Fujita, Makoto Fujita, Keigo Fuchi, Shinya Fukuda, Naofumi Hara, Naoki Hirai, Toshiro Hiromoto, Akira Horiuchi, Takashi Inoue, Junzo Ishii, Masaaki Iwasaki, Hiroyuki Kansaku, Yukitoshi Kubo, Makoto Matsuo, Shigeru Nishizawa, Takahiro Ohno, Daisuke Okamoto, Hikoh Okuda, Haruhiko Saito, Tsuyoshi Sakai, Hisakatsu Sakurai, Kazushi Shibata, Akira Shimizu, Tetsuo Sugimoto, Masatsugu Tsuji, Risa Ueda, Hiroyuki Yamada and Hiroshi Yoshimi. (2002). The Report of the Committee on Brand Valuation. The Ministry of Economy, Trade and Industry of the Government of Japan, June 24, 2002.

Huang, J. (2015). A Review of Brand Valuation Method. Journal of Service Science and Management, 2015, 8, 7176.

Keller, K. L. (2003). Strategic Brand Management: Building, Measuring, and Managing Brand Equity, $2^{\text {nd }}$ ed. Upper Saddle River, NJ: Prentice-Hall.

Ehrhardt, Michael C. and Eugene F. Brigham. (2011). Financial Management: Theory and Practice, 
Thirteen Edition. South-Western: Cengage Learning.

Muqaddas, M.F. and Ishtiaq Ahmad. (2016). Determinants of Brand Equity: An Empirical Study of it Industry. SEA Practical Application of Science, Volume IV, Issues 3 (12)/2016. p. 555560 .

Paramasivan, C. and T. Subramanian. (2012). Financial Management. New Delhi: New Age International (P) Limited, Publisher.

Penrose, E. T. (1959). The Theory of the Growth of the Firm. New York: John Wiley.

Sajid, M., A. Mahmood and H. M. Sabir. (2016). Does Financial Leverage Influence Investment Decisions? Empirical Evidence From KSE-30 Index of Pakistan. Asian Journal of Economic Modelling, 2016, 4(2): 82-89.

Tirole, J. 1990. The Theory of Industrial Organization. Cambridge, MA: MIT Press.

Ukiwe, Alladin O. (2009). The Joint Impact of Brand Value and Advertising on
Corporate Financial Performance and on Stock Return: A Case study of the Computer Industry. Disertasi. Walden University.

Varma, Aparna J., Ashwini J., and Vinutha R. (2018). Determinants of Brand Equity in two Wheeler Industry: A Study with Special Reference to Hero Motocorp in Mysuru Market. International Journal of Trend in Scientific Research and Development (IJTSRD), Volume 2. Issue 6, Sep-Oct 2018.

Wardianto, K. Bagus. Taher Alhabsji, Sri Mangesti Rahayu, and Nila Firdausi Nuzula, (2018). The Effects of Brand Equity on Firm Value and Profitability in Indonesia. Russian Journal of Agricultural and Socio-Economic Sciences. 9(81), September 2018. DOI https://doi.org/10.18551/rjoas.201809.24 .

Wernerfelt, B. (1984). A Resource-Based View of the Firm. Strategic Management Journal, Vol. 5 No. 2, pp 171-180. 